\title{
Comments upon Receiving the John Howland Award: Scholarship and Public Policy
}

\author{
JULIUS B. RICHMOND
}

Department of Social Medicine, Harvard Medical School, Boston, Massachusetts 02115

It is with a deep feeling of humility that I accept this honor from the American Pediatric Society, for I am much in awe of the illustrious people who preceded me. This is accentuated by the fact that I have had the good fortune to have been at the first presentation of the Award by Dr. Grover Powers to Dr. Edwards A. Park at the 62 nd meeting of the Society in 1952 and to have known all the recipients.

I take my reassurance from my belief in the infallibility of the process of peer review. My knowledge of the intellectual power of the members of the Council forces me to assume that they lost none of their critical faculties in this year's selection process.

This occasion is an appropriate one to express appreciation to many who have contributed so much to my development. I certainly cannot do justice to all of them.

First, I would mention Dr. Henry Poncher, my chief in pediatrics, who opened my eyes to the possibility of an academic career. He served as the Secretary of this Society from 1946 to 1951; hence, I became aware of the significance of its role in American pediatrics early in my career. In those days, when we met at places like the Red Lion Inn at Stockbridge, the Skytop Inn, and the Inn at Buck Hill Falls in Pennsylvania-among other quaint places- the annual meeting had the aura of a spring festival.

Second, I would mention my parents and all the members of my family from whom I had the good fortune to derive and have reinforced a social conscience and intellectual curiosity. To say more would convert this into too sentimental an occasion.

Third, I must pay tribute to many colleagues with whom I have collaborated. I have been unbelievably fortunate to have been associated with many congenial and creative people. I will mention only two briefly. Dr. David Shakow, one of the great psychologists of this century and one of the founders of clinical psychology, taught me much. At a time when there were no organized programs in child development for pediatricians, he helped me chart a course of self-education and training. It was an ongoing tutorial over a brown-bag lunch at his desk. And I never came away with fewer than three books under my arm. The second is Dr. Milton Senn. Although I did not study with him, he was my role model, for he demonstrated, by example, that psychologic and social developmental issues could be incorporated in pediatric education and training.

And last, but by no means least, I express my appreciation to the many students I have had over the years. I don't nurture much nostalgia for the good old days, for my view is that the students keep getting better. In a recent teaching program for our 3rd-year students, I couldn't help but be impressed by their high intelligence, sensitivity, and commitment. And we should all be pleased by the increasing numbers of women among them! We should, however, be doing better in recruiting students of minority group background.

As Leon has told you, I have had the opportunity to move back and forth between academic life and public policy respon-

Reprint requests: Julius B. Richmond, M.D., John D. MacArthur Professor of Health Policy, Emeritus, Department of Social Medicine, Harvard Medical School 641 Huntington Avenue, Boston, MA 02115. sibilities over my career. This occasion stimulates me to reflect on the relationship between the academic community and public policy and to do this in the context of the rich history of this Society.

Last year, we celebrated the 100th anniversary of the American Pediatric Society. The founders were prescient in recognizing the need for a national research forum. The advances in the natural sciences that were to create a revolution in medical education and research had not yet been consolidated. Virchow's contributions to the founding of cellular pathology were recent; only 7 years earlier, Koch had described the tubercle bacillus; Weichselbaum didn't describe the meningococcus until 4 years after the founding of the Society; Pasteur was still making his many contributions to our knowledge of pathology in plants, animals, and people. Roentgen had not quite discovered x-rays.

Clearly, there was a need to apply these scientific developments to gain new knowledge to further the health of children. This is well stated in the Society's constitution (1):

The objects of this Society shall be to bring together men and women for the advancement of the study of children and their diseases, for the prevention of illness and the promotion of health in childhood, for the promotion of pediatric education and research, and to honor those who, by their contributions to pediatrics, have aided in its advancement.

The responsibility of the Society for generating new knowledge was provocatively articulated by Dr. Thomas Morgan Rotch, Professor of Pediatrics at the Harvard Medical School and the first full-time professor of pediatrics in the United States, in his Presidential Address, "Iconoclasm and Original Thought in the Study of Pediatrics":

\begin{abstract}
[The Society] must in the early years of its existence be iconoclastic. It must break down and sweep away these misleading structures, clear the ground of these undesirable remnants of the past, get down to virgin soil, and then, by original research, build up our new fabric on a stable basis. [He advocated studying human development] from embryo to infant and infant to child and child to adult [whereas in the past] the very opposite method had been adopted; the most careful attention being paid to adult anatomy and physiology, and then deductions made backward from adult to child,- - a retrograde means of acquiring knowledge, which has proved eminently unsuccessful.
\end{abstract}

He then suggested what later became institutionalized in medical education and research: the inclusion of the sciences basic to medicine. Thus, he went on to propose "[making] use of the experts in their several branches, whether it be chemistry or physiology, anatomy or bacteriology, to strengthen and make stable our general deductions as clinical investigators" (2).

I present this historical context, for it provides me an opportunity to relate the primary mission of the Society as portrayed by the founders to the formulation of public policy. As I have struggled with how policy is formulated in a large pluralistic society such as ours, I have visualized the dynamics as an interaction among our knowledge base, our political will, and 
our society strategies (Fig. 1). The role of the members of this Society in generating the knowledge base that spurred the great advances in child health does not need detailing in this group.

But we should note that the tremendous improvements during this century in infant and childhood morbidity and mortality are due in no small measure to the contributions of members of this Society (many of them recipients of the Howland Award) to the knowledge on which public health practices are based (Figs. 2 and 3). The newer knowledge of metabolism, nutrition, infectious diseases and immunology, endocrinology, cardiology, neurosciences, imaging, and hematology and oncology seems like science fiction to anyone who attended medical school before World War II, as I did.

But what of the other two components and the shaping of

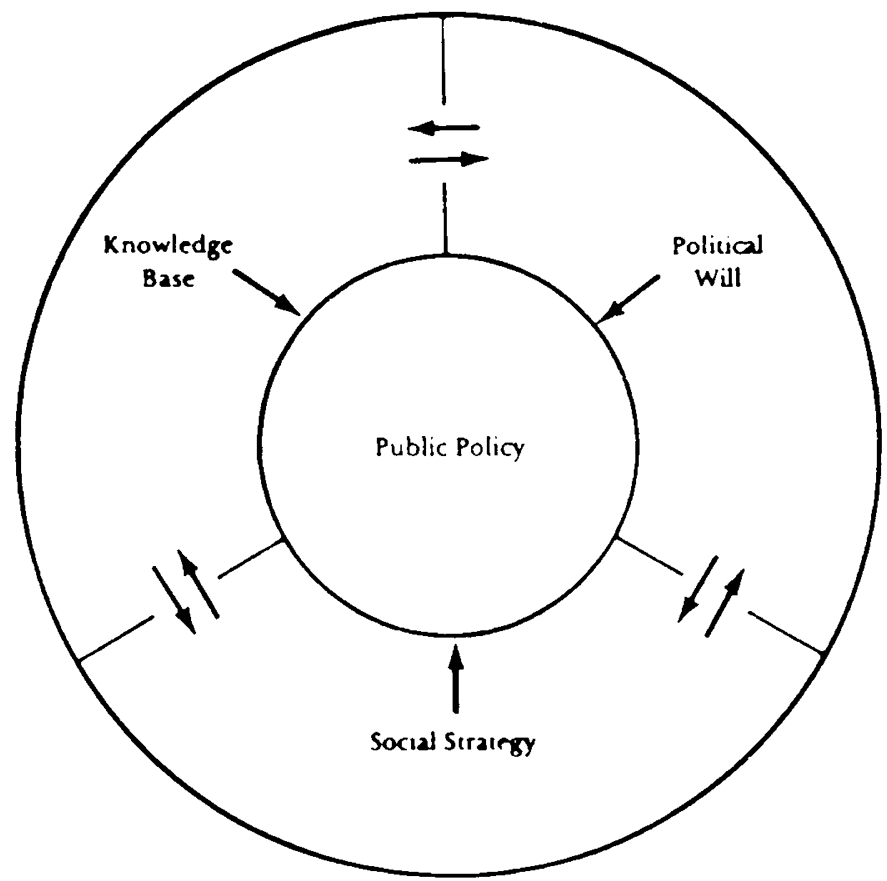

Fig. 1. Development of public policy. Source: Richmond JB, Kotelchuck M 1983 Political influences: rethinking national policy. In: McGuire CH, Foley RP, Gorr A, Richards RW (eds) Handbook of Health Professions Education. Jossey-Bass, San Francisco, pp 386-404. Reprinted with permission.

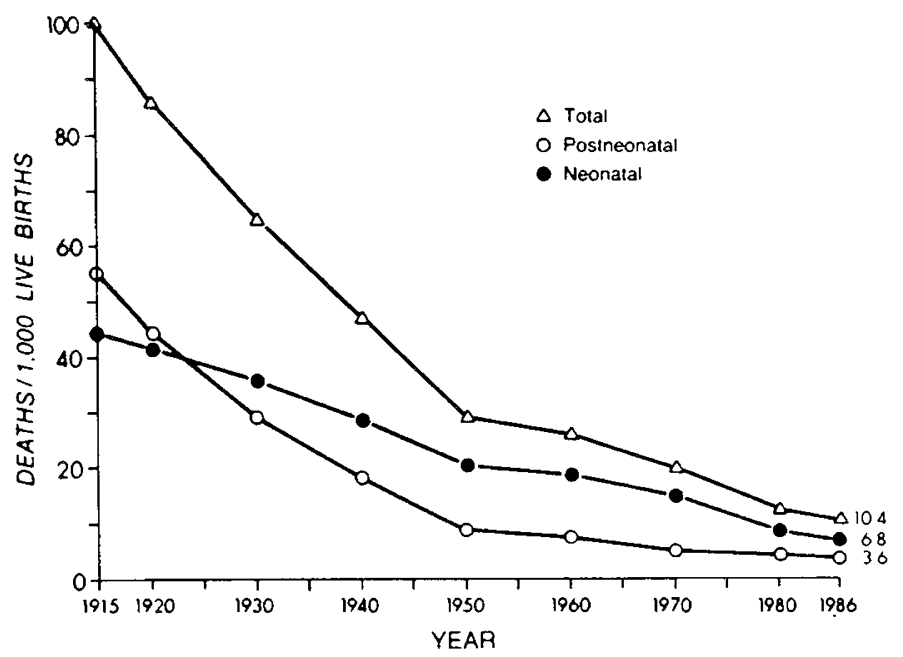

Fig. 2. Infant mortality in the United States, 1915 though 1986 (deaths per 100000 population). Source: Hoekelman RA, Pless BP 1988 Decline in mortality among young Americans during the 20th century: prospects for reaching national mortality reduction goals for 1990 . Pediatrics 82:582-595. Reprinted with permission.

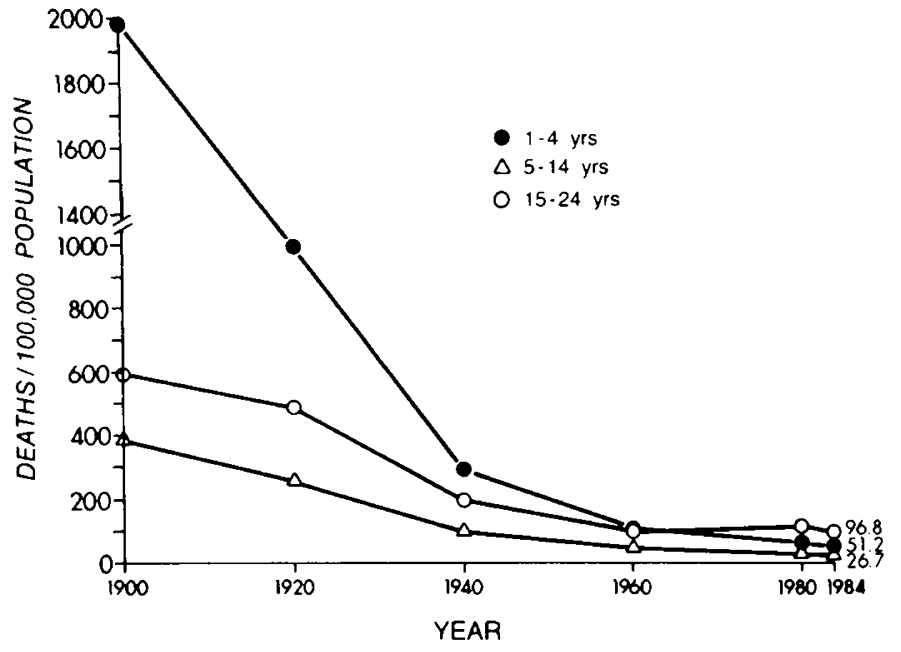

Fig. 3. Mortality among the young in the United States, 1900 through 1984 (deaths per 100000 population). Source: same as for Figure 2. Reprinted with permission.

policy? I define political will as generating support and resources-not only in the public sector, but in the private sector as well. (I would remind you that $60 \%$ of health expenditures are in the private sector.) The term "social strategies" refers to developing systematic approaches to applying the knowledge and technologies we have in concert with the political will. That these are not always in balance can be illustrated by the history of smallpox eradication from the world. We had the technology for accomplishing this years before it was done. But in the 1960s, when the political will was mobilized in the World Health Organization, the task was completed within a decade and smallpox was declared eradicated in 1980 .

Thus, for the improvement of the health of populations, knowledge is not enough; some groups must be prepared to develop the social strategies and political will. I submit that we generally are not very good social strategists, for we have the knowledge base to do much better for our children in the United States, yet our low birth weight and infant mortality rates remain too high, our immunization rates remain too low, our educational programs-especially for low-income children-have deteriorated, and we have permitted a $10 \%$ increase in the number of children living in poverty to develop over the last decade.

To return to the role of this Society, we have heard recurrent debates in our meetings about whether to take stands on social or political issues. Each time the debate is framed as a new issue. It is important, therefore, to note that the tension between scholarship and action goes back to the early years.

It appeared in the discussion of a paper presented at the $21 \mathrm{st}$ annual meeting in 1909 by none other than the same Dr. Thomas Morgan Rotch. I would remind you that in his earlier Presidential Address, he clearly defined the need to enrich the knowledge base. His paper on this occasion was titled "The Position and Work of the American Pediatric Society Toward Public Questions" (3). The presentation was an effort to blend science and social action, for Dr. Rotch shared the concern of social reformers of the day with the unfavorable impact of child labor on the health and welfare of children. Using the new x-ray techniques, he developed the first effort at determining bone age. His inference was that these methods might provide better standards for determining when children might be eligible for the work force.

The paper precipitated lengthy discussion. The long-time secretary of the Society, Dr. Samuel S. Adams said (3).

...we should now, even at this late day, after 21 years of existence, and having reached our majority, assume the position to which we are entitled, that of a body competent to speak with authority on all questions of public interest in regard to the health and development of the child. 
Two respected members dissented. Dr. Isaac Abt of Chicago said, "It seems to me that it is our mission to stimulate and encourage scientific work to the very highest degree. It should be farthest from our purpose to become entangled in political or legislative questions" (3), and Dr. L. Emmett Holt of New York added (3):

I should feel sorry to see a large part of the work of this Society devoted to subjects of this kind, which, though of sociologic interest, are not so much along the line of work of most of us as other matters more strictly medical. I believe we can do our best work along the lines of research.

Dr. Rotch expressed sharp disagreement. The dialogue seems familiar to many of us who have heard similar debates in these meetings over the years.

Many of the tensions over the years were resolved in pragmatic ways by the actions of individuals and groups of members. Thus, as the number of pediatric practitioners grew, a small group of members saw the wisdom of developing a new organization that could be inclusive and reflect the concerns of practitioners for the health and welfare of children and their families. For this purpose, the American Academy of Pediatrics was founded in 1930. As the need to set eligibility standards for practice developed, members became influential in organizing the American Board of Pediatrics in 1933. We should also note the role of members in fostering the development of the Society for Pediatric Research in 1932 to take into account the growing numbers of young pediatric investigators. Thus, the creativity of the membership led to inventiveness in setting up new institutional forms.

From a personal perspective, I have some reason to be optimistic that we can at least raise the right questions for the shaping of policy. Please permit me to draw on some personal experiences. In the early 1960s, Dr. Bettye Caldwell and I and, coincidentally, three other groups, were studying the development of young children growing up in environments of poverty. We noted rather striking developmental attrition among them (Fig. 4). Fortuitously, the civil rights revolution with its focus on poverty was in progress. But one can wonder, in retrospect, why it took us so long to discover this very significant phenomenon, for there had been no dearth of studies on the development of young children. It is clear that those studies were conducted predominantly in university settings in which the subjects were mainly the children of other faculty members! Although such knowledge is helpful, we were overlooking some important groups in society.

The question followed naturally concerning the possible pre-

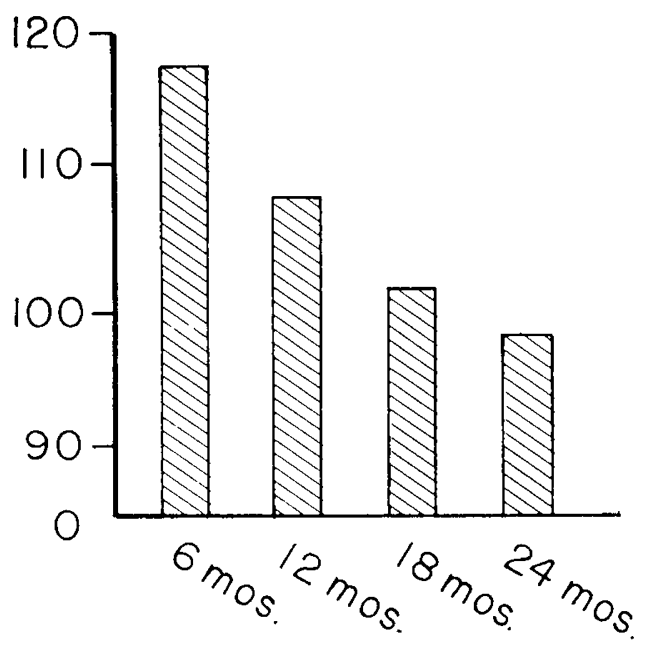

No Intervention

Fig. 4. Intelligence quotients of 23 subjects (measuring instruments $=$ Cattell Infant Scale and Stanford-Binet). Source: Richmond JB 1970 Disadvantaged children: what have they compelled us to learn? Yale $\mathbf{J}$ Biol Med 43:127-144. Reprinted with permission. vention of such developmental attrition. Fortunately, in a day care program, we demonstrated that this was possible. These data certainly reveal the plasticity of human potentialities (Fig. 5). Coincidentally, the Office of Economic Opportunity was established and I was asked quite unexpectedly to translate these findings into a national comprehensive child development program, which is what Head Start really is. Time doesn't permit a detailed presentation of its impact, but I would observe that we are not very effective advocates, for in this 25 th anniversary year, the program reaches only about $20 \%$ of those in need. This may represent the greatest loss of human potential in the nation, which we can ill afford. But that may well change this year, as there seems to be consensus for significant increases in support. We should move forward to making the program available to all in need.

As an example of asking the right policy questions, I would point to the recent study supported by the Robert Wood Johnson and Pew Foundations. The study asks a straightforward question: Does a well-designed program of intensive early child care make a difference in the developmental outcomes of premature lowbirth-weight infants? The policy implications for potentially enhancing the development of vulnerable infants are obvious at a time when we are trying to improve our preventive and management programs for developmental disabilities. Our sophistication is growing in study design, for the research uses the strategy of a multicenter study, which is so widely used in clinical research. Dr. Ruth Gross has reported favorable effects of the intervention for many of these children. There are many policy implications of these findings. (4)

We sometimes encounter situations in which our political will clearly outruns our knowledge base. This is particularly true currently around the issues of drug abuse. The perception is one of crisis and there are cries for some "instant fix." When the drug bill was debated in Congress last year and billions of dollars were at stake, it was sad that the major attention was on the death penalty and law enforcement. In my view, this reflected our lack of basic knowledge about habituation. Thus, aside from suggesting more resources for treatment (which is a desirable goal), we had very little to offer, especially for prevention.

Thus, one area in need of study is the natural history of the developmental processes through which young adolescents go in their path from nonusers to experimenters (a natural, if not inevitable, part of the adolescent experience) to habituation or to more healthy management of these kinds of activities. There has been a great deal of attention given to the so-called natural

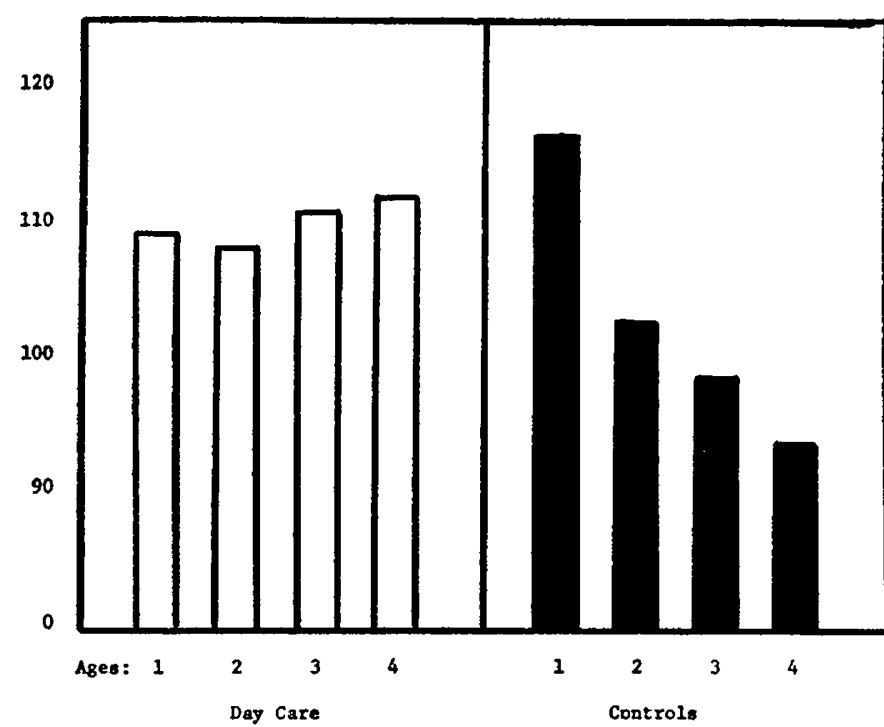

Fig. 5. Cross-sectional mean developmental test scores for day care and control children tested at ages 1,2,3, and 4. Source: same as for Figure 4. Reprinted with permission. 
progression through the use of one addictive substance to the next (for example, cigarettes to marijuana), the so-called gateway effect, but there is surprisingly little research on the relationship between the developmental patterns of an individual child's psychosocial growth, that is, the growing social and personal understanding the younger adolescent has of the effects of these activities.

For these reasons, my colleagues and I at Harvard are just beginning a longitudinal study of culturally diverse groups in early adolescence designed to understand better the relation between psychosocial development, on the one hand, and the course and probability of habituations on the other. Of course, we realized that both an individual's temperament and the social context in which he or she functions will have strong influences on the course of an individual's habit patterns, but we are betting that this course will be strongly mediated by the maturity of the psychosocial processes the individual brings to bear on habits of personal-and interpersonal-health. If we are on the right track, we may have in hand some important data from which we may be able to design more effective interventions.

It is apparent that I view the shaping of health policy in this large, open, pluralistic society as a complex process. Our knowledge base, political will, and social strategies are not always in balance. But a clear concept of these dynamics will permit us to exercise our leadership responsibilities more effectively to bring better health to our children and their families.

I have already commented on the honor that comes with this award. One doesn't work to receive awards. I have been fortunate enough to have spent my life doing what I most enjoy: trying to learn more about how we can help children and families. But when praise does come, perhaps I can turn to the comforting words of a novelist, Isaac Bashevis Singer. When he received New York City's highest cultural award-the Handel Medallion, he responded by saying:

My grandfather, who was a rabbi, once in a sermon asked a question which embarrassed almost the whole audience. He said, "Why is the Almighty so eager to get so much praise? Three times a day you have to pray to Him and say how great He is, how wonderful. Why should the creator of all the stars, all the planets, be so eager for a little praise?'

And my grandfather said, 'Wait, I have an answer to this question.' And they said, 'What is the answer?' And he said, 'The Almighty knows from experience, from divine experience, that when people stop praising Him they begin to praise one another.' This is what, my grandfather said, the Almighty does not like.

But anyhow, small people that we are, we enjoy sometimes some praise, especially if it comes from the mouths of good people.

\section{REFERENCES}

1. Faber HK, McIntosh R 1966 History of the American Pediatric Society, $1887-$ 1965. McGraw Hill, New York, p 367

2. Rotch TM 1891 Iconoclasm and original thought in the study of pediatrics. Trans Am Pediatr Soc III:6-9. In: Bremner RH (ed) Children \& Youth in America: A Documentary History, Vol II, 1866-1932. Harvard University Press, Cambridge, MA, pp 819-820

3. Rotch TM 1909 The position and work of the American Pediatric Society toward public questions. Trans Am Pediatr Soc XXI:8-39. In: Bremner RH (ed) 1971 Children \& Youth in Society: A Documentary History, Vol II, 1866-1932. Harvard University Press, Cambridge, MA, pp 821-828

4. Infant Health and Development Program 1990 Enhancing the outcomes of low-birth-weight, premature infants: a multisite randomized trial. JAMA 263(21):3035-3042 